\title{
PROCEDURES FOR RESIDUAL STRESS ANALYSIS IN TEXTURED AND IN COARSE GRAINED MATERIALS
}

\author{
W. REIMERS and R. DUPKE \\ Hahn-Meitner-Institut Berlin, Bereich Strukturforschung 14109 Berlin, Germany
}

(Received 5 November 1994; in final form 5 December 1994)

\begin{abstract}
For the investigation of residual stresses by means of X-ray diffraction, special procedures for the registration and evaluation of the experimental strain data are necessary for textured and coarse grained materials. In both cases inhomogeneous diffraction intensity patterns are present which lead to the formation of intensity poles or even to Bragg reflections. Such experimental findings indicate also that the material properties within the investigated gauge volume are anisotropic so that the evaluation of the experimental strain up to stress values requires the introduction of anisotropic elastic constants. For the residual stress investigation of textured and fine grained materials averaging procedures using short wavelength radiation are discussed. A more detailed insight also in the microstress states may be obtained from the measurement of several different reflections whereby the effects of the elastic anisotropy may be corrected for by including the orientation distribution function as calculated from different poles figures. For coarse grained materials it is experimentally possible to determine the strain state of the individual crystallites so that their anisotropy is directly included in the evaluation of the stress data by using the single crystal elastic constants. The macroscopic residual stress values may then be obtained from the averaging over stress values of several crystallites.
\end{abstract}

KEY WORDS: Residual stresses, anisotropic materials, $\mathrm{X}$-ray diffraction, evaluation of diffraction data.

\section{INTRODUCTION AND BASIC PRINCIPLES}

$\mathrm{X}$-ray diffraction is the classical method for the nondestructive analysis of residual stresses. The reasons for the wide spread use of this method are based on several advantages: X-ray diffraction can be used on all crystalline materials. The analysis is performed nondestructively and yields the stresses with sign, absolute value and orientation of the main stresses. In case of multiphase materials like e.g. ferriticaustenitic steels the stresses can be measured in each individual phase so giving further information about microstresses.

The analysis of residual stresses by means of diffraction methods is based on Bragg's law:

$\lambda$ - wavelength

$$
\lambda=2 \mathrm{~d}_{\mathrm{hk} \mathbf{l}} \sin \theta
$$

$d_{\text {hkl }}$ - interplanar lattice distance

$\theta$ - diffraction angle 


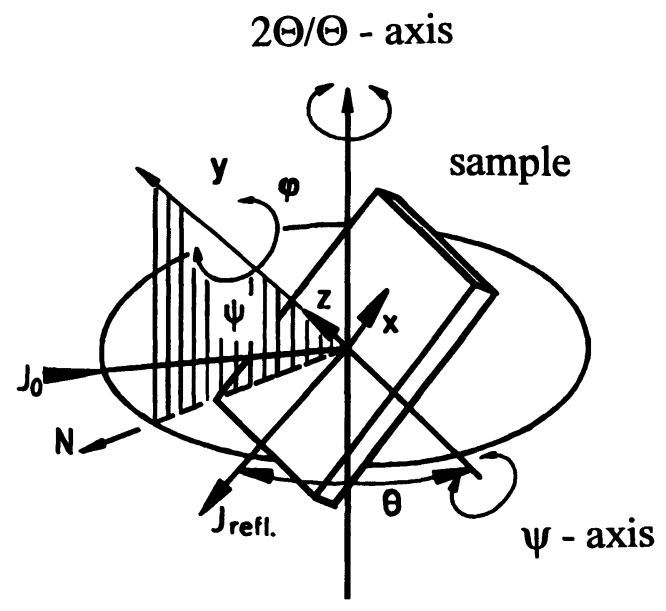

Figure $1 \psi$-diffractometer.

If stresses are present in the material, the interplanar lattice spacings are changed, which can be detected by a shift in the diffraction angle $\theta$. This experimental finding is then used to calculate the stresses by applying Hooke's law.

The most common procedure in studying the strain-stress state in the sample is the repeated measurement of the diffraction angle $\theta$ for different inclination angles $\psi$ of the sample surface relative to the scattering vector $\vec{N}$, Figure 1 .

From the reflection profile evaluation the d-values are obtained and plotted in a $d_{\varphi \psi}$ vs. $\sin ^{2} \psi$ diagram, where in most practical cases a linear relationship is present, Figure 2.

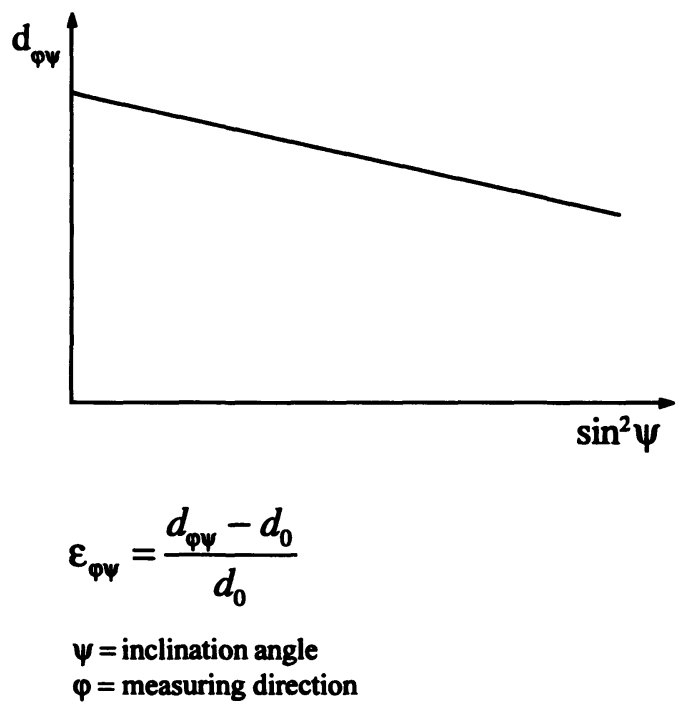

Figure $2 d_{\varphi \psi}$ vs. $\sin ^{2} \psi$ diagram. 
The slope $\mathrm{m}$ of the $\mathrm{d}_{\varphi \psi}$ vs. $\sin ^{2} \psi$ line is directly proportional to the stress value $\sigma_{\varphi}-\sigma_{33}:$

$$
\sigma_{\varphi}-\sigma_{33}=\frac{m}{1 / 2 s_{2}}
$$

$\sigma_{33}-$ stress tensor component perpendicular to the sample surface

$1 / 2 S_{2}$ - isotropic X-ray elastic constant

Since the stress value obtained according to the $\sin ^{2} \psi$-method (Macherauch and Müller, 1961 ) is based of the comparison of $d_{\varphi \psi}$-values in different sample directions, the procedure is nearly independent of the $d_{0}$-value of the stress free material. A further advantage has to be seen in the straight forward evaluation procedure. The $\sigma_{33}$ component may be mostly approximated to zero since the information depth of X-ray diffraction is limited to the near surface zone of some $10 \mu \mathrm{m}$. So generally two dimensional stress states are investigated by $\mathrm{X}$-ray diffraction.

Due to the penetration depth of neutrons, neutron diffraction is then used for the nondestructive analysis of volume stresses below the surface (information depth up to some $\mathrm{cm}$ ). In the interior of materials three-dimensional stress states have to be expected. The relationship between the experimental strain data $\varepsilon_{\varphi \psi}$ and the strain tensor components of the sample is then given by:

$$
\begin{aligned}
\varepsilon_{\varphi \psi} & =\frac{\mathrm{d}-\mathrm{d}_{0}}{\mathrm{~d}_{0}} \\
& =\varepsilon_{11} \cos ^{2} \varphi \sin ^{2} \psi+\varepsilon_{12} \sin 2 \varphi \sin ^{2} \psi \\
& +\varepsilon_{22} \sin ^{2} \varphi \sin ^{2} \psi+\varepsilon_{13} \cos \varphi \sin 2 \psi \\
& +\varepsilon_{33} \cos ^{2} \psi+\varepsilon_{23} \sin \varphi \sin 2 \psi
\end{aligned}
$$

Here, the measured strain value $\varepsilon_{\varphi \psi}$ generally depends on all six independent components of the strain tensor of the sample. Hence, at least six measurements in different sample directions are necessary for evaluating the symmetric $3 \times 3$ strain tensor.

The stress tensor is then obtained by applying the covariant formulation of Hooke's law for elastic and quasi isotropic media:

$$
\sigma_{\mathrm{ij}}=\frac{E}{1+v}\left(\varepsilon_{\mathrm{ij}}+\frac{v}{1-2 v} \delta_{\mathrm{ij}} \sum_{\mathrm{i}=1}^{3} \varepsilon_{\mathrm{ii}}\right)
$$

$\delta_{\mathrm{ij}}-$ Kronecker symbol with $\delta_{\mathrm{ii}}=1, \delta_{\mathrm{ij}}=0$

The described measuring and evaluation procedures may be applied to those polycrystalline materials where Debye fringes with homogeneous intensity distributions are observed as diffraction pattern. In the case of materials with preferred crystal orientation intensity poles are found in the measuring directions $\varphi \psi$ where an exceptional number of crystallites contributes to the diffraction intensity. In the case of coarse grained materials the Debye fringes may even split in localized Bragg reflections. So for the experimental analysis of the diffraction angles $\theta$ in both cases additional efforts for the selection of suited measuring directions $\varphi \psi$ are necessary.

Furthermore, the presence of inhomogeneous diffraction intensity patterns from the 
gauge volume under study caused either by texture or by an insufficient number of illuminated crystallites proves that the usual assumption about quasiisotropic material behaviour is not fulfilled. For the evaluation of the experimental strain data up to stress values the anisotropic materials properties have to be respected by the introduction of adequate anisotropic elastic constants.

\section{RESIDUAL STRESS ANALYSIS IN TEXTURED MATERIALS}

In textured materials non-linear $d_{\varphi \psi}$ vs. $\sin ^{2} \psi$ distributions are often found. The basic reason for this finding is the elastic and plastic anisotropy of the crystallites forming the material, which is not averaged out due to the preferred orientation distribution of the crystallites.

In a first approximation it is, however, often possible to overcome the problem by selecting d-values for the measurements, which exhibit high multiplicities so that the effects of preferred orientation distributions are nearly cancelled out in the reflection profiles. A typical example is the investigation of steel on the reflection group 1732 $+651\}$ using Mo-K $\alpha$-radiation (Hauk and Vaessen, 1983). This way, mostly linear $d_{\varphi \psi}$ vs. $\sin ^{2} \psi$ distributions are found, which allow the determination of macroscopic stresses.

A more detailed analysis of the stress states in textured materials needs information about the orientation distribution. For this the model of ideal crystallite orientation has been developed (Dölle and Hauk, 1978). Here, the crystallite orientation distribution is approximated by the superposition of different single crystal orientations. This way the intensity poles can be calculated, which is the presumption for the measurements. Moreover, the direction dependency of the elastic constants is obtained from the transformations of single crystal elastic constants into the measuring directions. If the effort is made to measure complete pole figures for different reflections (hkl), also the orientation distribution function (Bunge, 1969) can be established, which then allows a quantitative calculation of the anisotropic elastic constants of the material (Barral $e t$ al., 1985). Barral et al. have performed the calculation and the comparison with the experimental data for the Reuss limit, which represents the maximum effect of anisotropy, whereas most experimental studies on isotropic materials give evidence for the validity of the Hill's approximation (1952). Here, in good agreement with the Eshelby (1957) and Kröner (1958) models, the averaging over the Reuss and Voigt limits is proposed. It also has to be noticed that the discussed procedures for the calculation of the anisotropy of the elastic constants naturally only take into account the influence of elastic anisotropy. Mostly, however, a combination of elastic and plastic anisotropy is present. A striking example for the effect of plastic anisotropy is shown by the experimental data measured by Pintschovius (1992) on the elastically isotropic reflection $\{200\}$, Figure 3 .

The effects of plastic anisotropy are due to the fact that the crystalline structure offers preferred gliding systems for the plastic deformation. So on the microstructural scale of crystalline materials, differences in the yielding strengths of the crystallites are present, which depend in a first approximation on their orientation (Heyn, 1921 and Greenough, 1949). As demonstrated by a schematical stress-strain curve for two different crystallite orientations, the splitting in the yield strengths results in the presence of microscopical stresses after relaxation, Figure 4.

For evaluating the different stress states in crystallites with different orientations, 


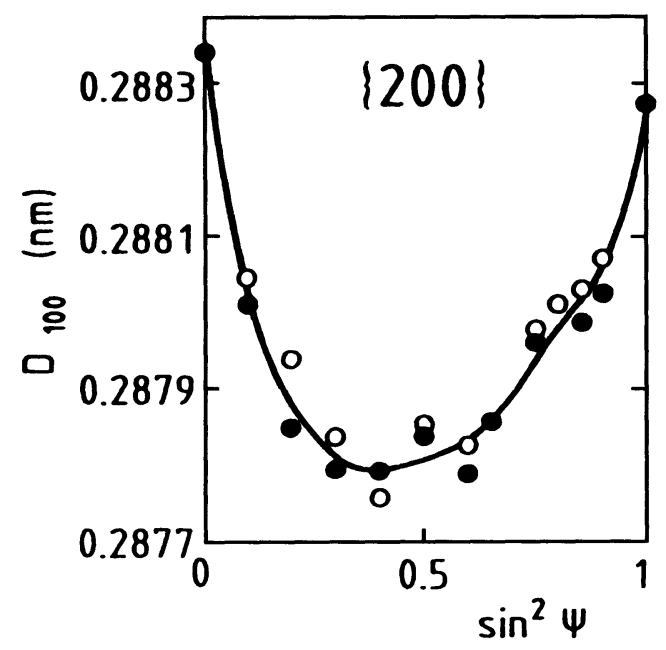

Figure 3 Nonlinear $d_{\varphi \psi}$ vs. $\sin ^{2} \psi$ distribution measured by neutron diffraction on the elastically isotropic $\{200\}$ reflection (Pintschovius, 1992).

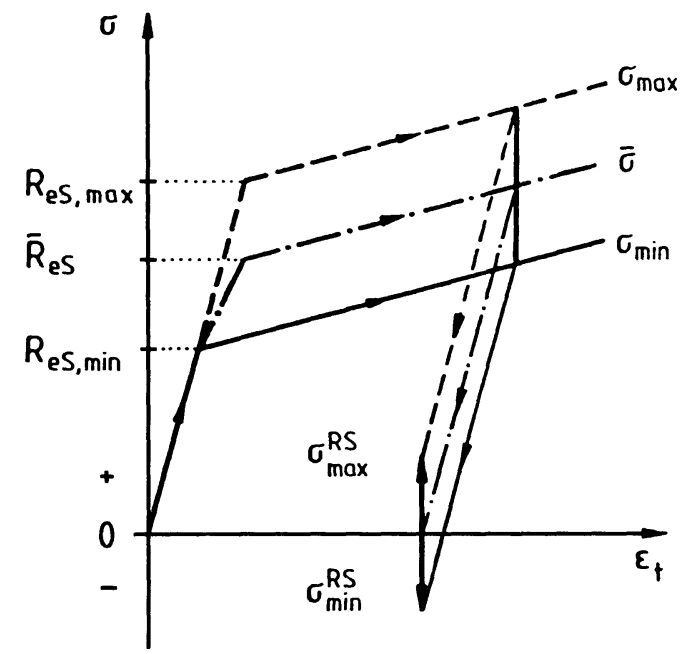

Figure 4 Development of microscopical residual stresses due to plastic anisotropy (Pintschovius, 1992).

the model of crystallite groups has been developed (Hauk and Stuitje, 1985a and 1985b). Here, crystallites with similar or identical orientations are summarized in a crystallite group. Since the determination of the strain state of a group requires measurements in different macroscopical sample directions $\varphi, \psi$ measurements on different reflections hkl are proposed. Measurements of different crystallite groups are displayed in Figure 5. 

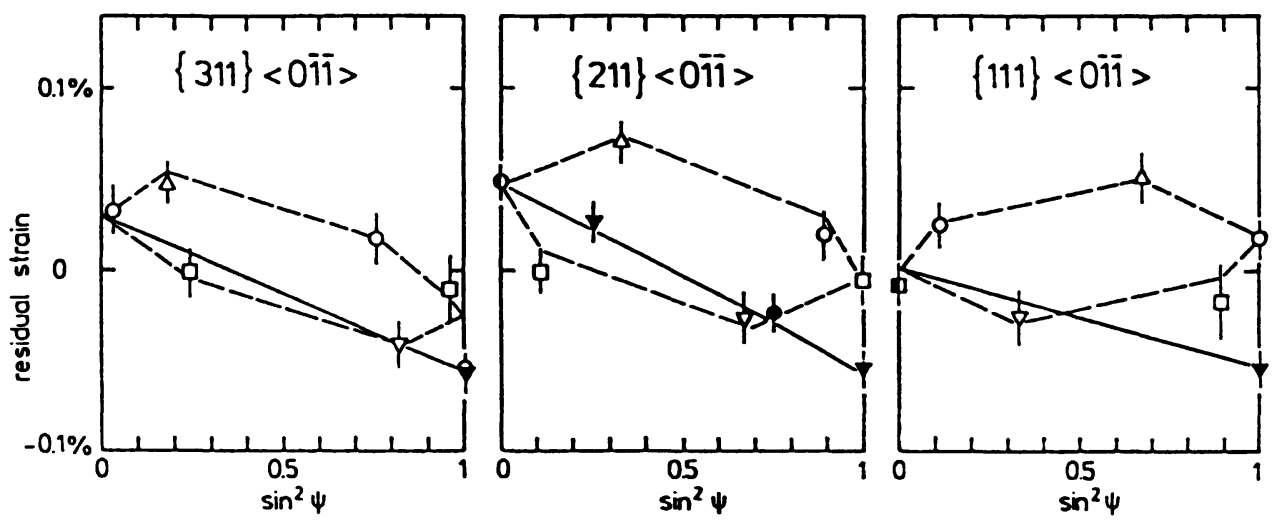

Figure 5 Strain distributions in different crystallite groups (Feja et al., 1987).

For calculating the stresses, the stress-strain relationship for single crystals is used:

$$
\varepsilon_{\mathrm{hk1}}=\sum_{\mathrm{i}=1}^{3}\left[\mathrm{~S}_{12}+\mathrm{S}_{0}\left(\alpha^{2} \alpha_{\mathrm{i}}^{2}+\beta^{2} \beta_{\mathrm{i}}^{2}+\gamma^{2} \gamma_{\mathrm{i}}^{2}\right)+\frac{1}{2} \mathrm{~S}_{44}\left(\alpha \alpha_{\mathrm{i}}+\beta \beta_{\mathrm{i}}+\gamma \gamma_{\mathrm{i}}\right)^{2}\right] \sigma_{\mathrm{i}}
$$

$\alpha, \beta, \gamma \quad$ - the cosines of the angles between the direction [hkl] and the crystallographic axes

$\alpha_{i}, \beta_{i}, \gamma_{i}$ - the cosines of the angles between the principal stresses $\sigma_{i}$ and the crystallographic axes

$\mathrm{S}_{11}, \mathrm{~S}_{12}, \mathrm{~S}_{44}-$ the single crystal elastic compliances

$S_{0}=S_{11}-S_{12}-\frac{1}{2} S_{44}$

Using this procedure and combining X-ray and neutron diffraction data, considerable microstresses in a cold rolled steel strip could be traced (Pintschovius et al., 1987 and Feja et al., 1987). For checking the balance of forces, the stresses in the different crystallite groups were weighted corresponding to their volume fractions and added. It is interesting to note that small non-zero stresses of $-35 \mathrm{MPa}$ in the rolling direction and $-20 \mathrm{MPa}$ in the transverse direction remained. Since a second crystalline phase could be excluded by the authors, these stresses were attributed to grain boundaries, which do not contribute to the diffracted intensity.

\section{RESIDUAL STRESS ANALYSIS IN COARSE GRAINED MATERIALS}

In the case of studying coarse grained materials by means of diffraction methods, the relation between gauge volume and experimental resolution to grain size is decisive. 
Materials are defined as coarse grained when the Debye fringes under the given experimental conditions are splitted in localized Bragg reflections, which can be attributed to individual crystallites.

Applying X-ray diffraction where in general only the near surface crystallites contribute to diffraction pattern, the Debye fringes are usually splitted for crystallite diameters of $\varnothing \geq 50 \mu \mathrm{m}$. By additional sample movements during the measurement, e.g. rotation and inclination, the number of reflecting crystallites can be increased, so that the condition of quasi isotropic behaviour of the gauge volume may be fulfilled up to grain sizes of approximately $\varnothing \approx 200 \mu \mathrm{m}$. Using synchrotron radiation, however, separated Bragg reflections may already be observed at crystallite diameters of $\varnothing \approx 20 \mu \mathrm{m}$ due to the high parallelity of the radiation. For neutron diffraction investigations a gauge volume of some $\mathrm{mm}^{3}$ is usual due to intensity reasons. Grain size effects on the diffraction pattern are therefore to be expected at crystallite diameters of $\varnothing \approx 1 \mathrm{~mm}$.

In those cases where individual Bragg reflections are observed the single crystal anisotropy has to be considered in calculating the stresses from the experimental strain data. For this an evaluation of the orientation of the crystallites under study is necessary. Therefore in a first step the spatial orientation of two independent reflections (hkl) of the crystallite under study has to be determined. Using a fourcircle diffractometer, this may be done in a straight forward and efficient way. The details of this procedure have already been described elsewhere (Reimers, 1992a). From the knowledge of the spatial orientation of these two reflections the orientation matrix, which relates the crystallographic axes system to the fixed laboratory system can be established. From there on the diffractometer settings for every reflection (hkl) to be studied are calculated and the precise reflection position is determined experimentally by a centering routine. So this method is well suited for an automized measuring routine, which gives the strain tensor based on the experimentally determined diffraction angles $2 \theta$ for several reflections of an individual crystallite. Since the orientation of the crystallite has been determined the stress tensor components $\sigma_{\mathrm{ij}}^{\text {crystallite }}$ are calculated from the experimental strain tensor components $\varepsilon_{\mathrm{ij}}^{\text {crystallite }}$ by applying Hooke's law for anisotropic materials:

$$
\sigma_{\mathrm{ij}}^{\text {crystallite }}=\sum_{\mathbf{k}, 1} \mathrm{c}_{\mathrm{ijk} \mathbf{l}} \varepsilon_{\mathrm{kl}}^{\text {crystallite. }} ; \mathrm{i}, \mathrm{j}, \mathrm{k}, \mathbf{l},=1,2,3
$$

$\mathrm{c}_{\mathrm{ijk} \mathbf{1}}$ - single crystal elastic constants

For comparing the stress states in different crystallites, their stress tensors have to be transformed into a common reference system, e.g. the macroscopic sample system.

The stress values obtained by the single grain measuring and evaluation technique represents the sum of the first and second order stresses (Macherauch et al., 1973). So, by studying several neighboured grains, the stress variations as well as the averaged stress state (macroscopical stresses) are accessible. Stresses of the third order can be obtained either by analysis of the $2 \theta$-profile or as a function of sample translation in respect to the measuring spot (X-ray or synchrotron radiation). So this diffraction technique allows the analysis of the residual stress state in coarse grained materials but it can also be used for studying the factors determining the deformation behaviour on the microstructural scale of polycrystals. Examples have been presented elsewhere (Reimers et al., 1992b).

For demonstrating further possibilities of the single grain measuring and evaluation technique, some results of residual stress investigations on the coarse grained Ni-base alloy IN 939 before and after plastic deformation shall be summarized. 
IN 939 is a $\gamma^{\prime}$-hardened alloy. Besides the stress development as a function of external loading also the stresses between the $\gamma$-matrix and the $\gamma^{\prime}$-particles are of interest since these microscopical stresses are made responsible for some of the excellent mechanical-technological properties, e.g. the high temperature creep resistance.

From the sample material flat tensile specimens were prepared by electroerosion and subsequent electrolytical polishing of a surface zone of approximately $50 \mu \mathrm{m}$. Since the heat impact of the electroerosion extends over a depth $\sim 200 \mu \mathrm{m}$, this way tensile residual stresses could be produced in the near surface zone, which were then quantitatively analysed by $\mathrm{X}$-ray diffraction. The average grain diameter in a specimen is $\varnothing \approx 1-2 \mathrm{~mm}$. In these grains the $\gamma^{\prime}$-particles with a diameter of $\varnothing \approx 200 \mathrm{~nm}$ are orientationally coherent with the matrix. Since furthermore the lattice parameters of $\gamma$ and $\gamma^{\prime}$ differ only in the order of magnitude of $1 \%$, the reflections of the two phases are superimposed, Figure 6.

The analysis of the reflection profiles in different crystallite directions revealed the same $2 \theta$-splitting and the same intensity ratios for the $\gamma$-and the $\gamma^{\prime}$-phase. So in a first step the reflection profiles were evaluated using the center of gravity method. These data then result in integral residual stress values for the crystallite under study, which represent the sum of first and second order stresses. The in-plane stresses for the investigated crystallites are displayed in Figure 7.

As discussed by Reimers (1989), the stress variations from grain to grain are due to the elastic anisotropy of the crystallites and to the crystallite-crystallite interactions in the polycrystal. The averaging over the stress tensor components for the investigated crystallites gives values of $\sigma_{11}=(350 \pm 140) \mathrm{MPa}$ and $\sigma_{22}=(450 \pm 100) \mathrm{MPa}$. These stress values are the macroscopic surface stresses (first order stresses), which are due to the above mentioned sample treatment. Consequently after further electrolytical polishing the macroscopic stresses are reduced, Figure 8.

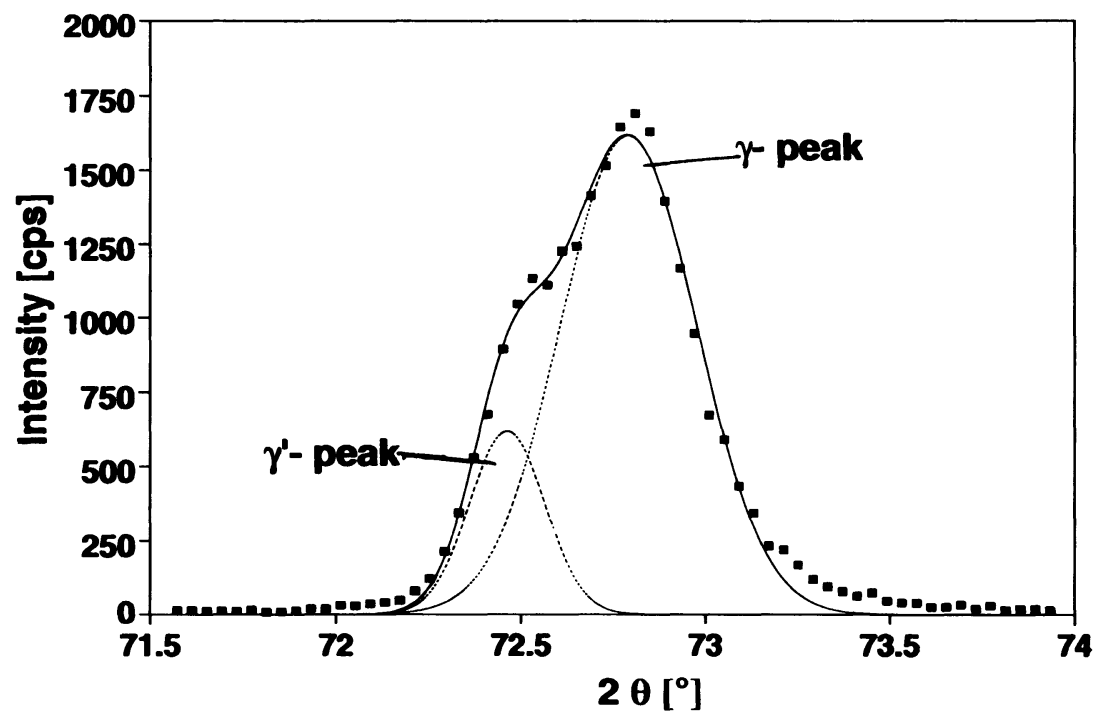

Figure $6 \mathrm{X}$-ray reflection profile from the $\gamma^{\prime}$-hardened Ni-base superalloy IN 939 . 


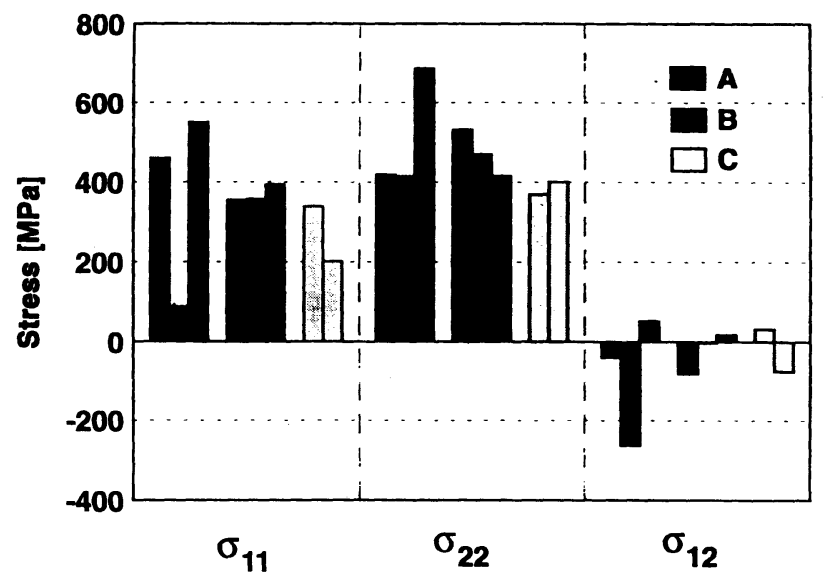

Figure 7 Stress values for the investigated crystallites.
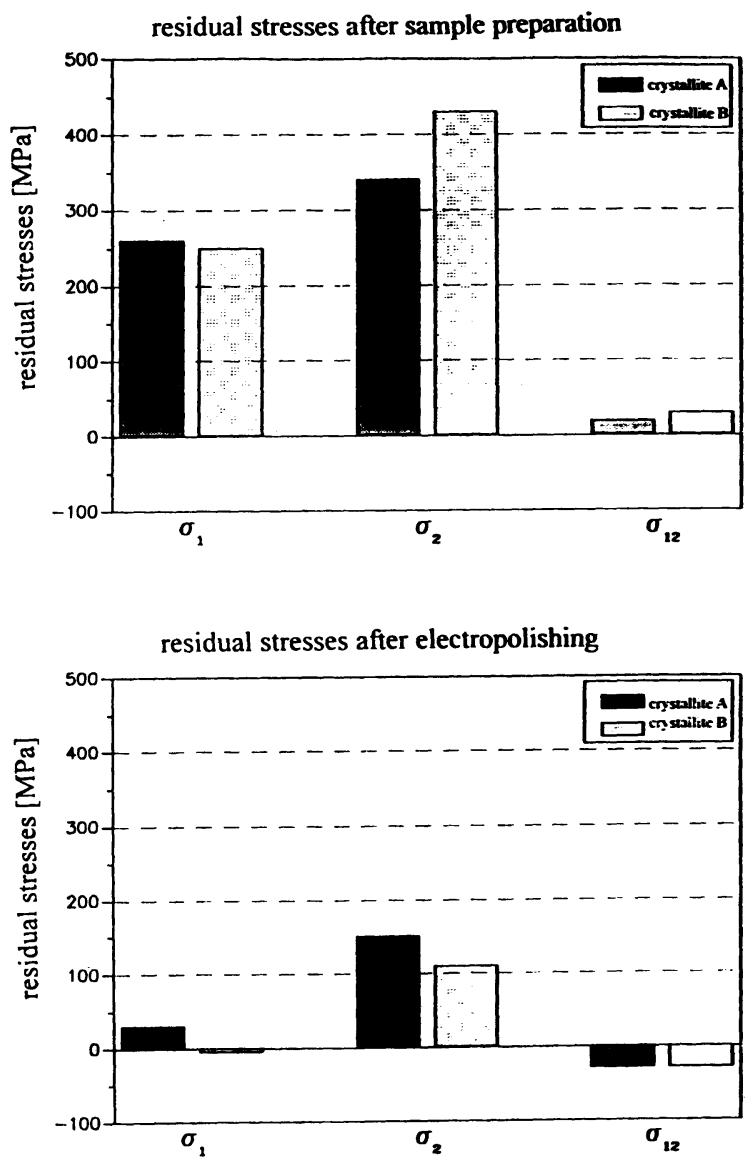

Figure 8 Residual stresses at the sample surface, before and after electrolytical polishing. 
A more detailed insight in the actual stress situation in the Ni-base alloy IN 939 can be obtained by also analysing the stresses in the $\gamma$ - and the $\gamma^{\prime}$-phases. For this, the reflection profiles (see Figure 6) are evaluated separately for $\gamma$ and the $\gamma^{\prime}$. The intensity analysis yields the volume ratio of the phases. In agreement with the data published by Delargy and Smith (1982) the $\gamma^{\prime}$-volume was determined to (30 \pm 5$) \%$. The splitting in $2 \theta$ of the $\gamma-\gamma^{\prime}$-profiles gives the corresponding $\Delta d$-values. These experimental data are composed from two components.

1. The difference in the crystallographic lattice parameters of the $\gamma$-and the $\gamma^{\prime}$-phase due to the different chemical composition. This different is used for the calculation of the $\gamma$ - $\gamma^{\prime}$-misfit:

$$
\delta=\frac{a_{\gamma^{\prime}}-a_{\gamma}}{1 / 2\left(a_{\gamma^{\prime}}+a_{\gamma}\right)}
$$

2. The individual strain states of the $\gamma$ - and the $\gamma^{\prime}$-phase due to the coherency of the phases. In this context it has to be mentioned that the heat treatment of the material strongly influences the degree of coherency present in the heterogeneous material. It could be shown for some alloys by Nathal et al. (1985) that an extensive heat treatment reduces the coherency until the " unconstrained misfit corresponding to Equation (7) is achieved.

So from the point of view of diffraction investigations at the given material the analysis of the $\Delta \mathrm{d}$-values directly gives the constrained misfit. At the sample material investigated in this study the misfit was determined to $\delta_{\text {constrained }}=3.8 \%$ whereby no anisotropy could be found. A further quantitative separation of this value into the parts unconstrained misfit and coherency strains requires the knowledge of the $d_{0}$-values for the $\gamma$ and the $\gamma^{\prime}$-phases.

Using $X$-ray diffraction with its near surface information depth, the $\mathrm{d}_{0}$-value can mostly be calculated by benifiting from the boundary condition $\sigma_{33}=0$. This, however, is not admitted in the case of heterogeneous materials. Especially the diameter of the $\gamma^{\prime}$-particles with less than $0.2 \mu \mathrm{m}$ in comparison to the penetration depth of the $\mathrm{X}$ radiation with $10 \mu \mathrm{m}$ indicates that already three dimensional stress states are registered. Therefore, the coherency stresses between the $\gamma$ - and the $\gamma^{\prime}$-phases had to be estimated by using the approximation proposed by Grose and Ansell (1981). Accordingly about $40 \%$ of the measured in-situ misfits are attributed to coherency strains. Using this assumption tensile coherency stresses of up to $300 \mathrm{MPa}$ in the matrix are calculated. Considering this data and adding the integral stress values summarized in Figure 7, maximum local tensile stresses up to $700 \mathrm{MPa}$ are present in the sample material.

The sample material was again investigated at defined intervals during low cycle fatigue tests, which were performed at $\mathrm{T}=850^{\circ} \mathrm{C}$, Due to the tensile stresses in the near surface zone, at an external stress level of $\sigma_{\text {ext }}=350 \mathrm{MPa}$ (uniaxial) plastic deformation was already observed. The residual stress analysis based on the integral evaluation of the stress profiles then yielded a macroscopic stress value in the loading direction of $\sigma_{22}=-150 \mathrm{MPa}$. This result is in agreement with the expected inhomogeneous deformation over the sample diameter. The near surface region is plastically deformed due to its tensile prestresses whereas the core of the sample stays in the elastic regime so that the relaxation of the sample leads to compressive stresses at the surface. The further analysis of the separated $\gamma$ - and $\gamma^{\prime}$-subprofiles supports this explanation and gives further insight. Since the tensile stresses are highest in the matrix as a consequence of the superposition of macroscopic and coherency stresses, the 
strongest changes of the stress values after external load are observed for the $\gamma$-phase. The $\gamma^{\prime}$-phase, however, shows compressive stresses in the juvenile sample. Consequently, this phase is much less affected by the external load and its stress values are less changed.

\section{References}

Barral, M., Sprauel, J. M. and Maeder, G. (1983). Stress measurements by X-ray diffraction on textured material characterised by its orientation distribution function (ODF), in: Eigenspannungen, Bd. 2, E. Macherauch, V. Hauk (eds.), Deutsche Gesellschaft für Metallkunde, Oberursel, 31-47.

Bunge, H.-J (1969). Mathematische Methoden der Texturanalyse, Akademie-Verlag, Berlin.

Delargy, K. M. and Smith, G. D. W. (1982). Phase Composition and Phase Stability of Alloy IN 939, Conf. Proc. "High Temperature Alloys for Gas Turbines", 705-719, Lüttich (Belgien).

Dölle, H. and Hauk, V. (1978). Einfluß der mechanischen Anisotropie des Vielkristalls (Textur) auf die röntgenographische Spannungsermittlung, Zeitschrift für Metallkunde, 69, 410-417.

Eshelby, J. D. (1957). The determination of the elastic field of an ellipsoidal inclusion and related problems, Proceedings of the Royal Society (London), A241, 376-396.

Feja, K., Hauk, V., Krug, W. K. and Pintschovius, L. (1987). Residual Stress Evaluation of a Coldrolled Steel Strip Using X-rays and a Layer Removal Technique, Materials Science and Engineering, 92, 13-21.

Greenough, G. B. (1949). Residual lattice strains in plastically deformed polycrystalline metal aggregates, Proceedings of the Royal Society (London), A197, 556-567.

Grose, D. A. and Ansell, G. S. (1981). The Influence of Coherency Strain on the Elevated Temperature Tensile Behaviour of Ni.-15Cr-Al-Ti-Mo alloys, Metallurgical Transactions, 12A, 1631-1645.

Hauk, V. and Vaessen, G. (1983). Röntgenographische Spannungsermittlung an texturierten Stählen, in: E. Macherauch, V. Hauk (eds.), Eigenspannungen, Vol. 2, Deutsche Gesellschaft für Metallkunde, Oberursel, 9-30.

Hauk, V. and Stuitje, P. J. T. (1985), Röntgenographische phasenspezifische Eigenspannungsuntersuchungen heterogener Werkstoffe nach plastischen Verformungen, Teil I, Zeitschrift für Metallkunde, 76, 445-451.

Hauk, V. and Stuitje, P. J. T. (1985). Röntgenographische phasenspezifische Eigenspannungsuntersuchungen heterogener Werkstoffe nach plastischen Verformungen, Teil II, Zeitschrift für Metallkunde, 76, 471-474.

Heyn, E. (1921). Eine Theorie der "Verfestigung" von metallischen Stoffen infolge Kaltreckens. Festschrift der Kaiser-Wilhelm-Gesellschaft, 121-131, Verlag J. Springer, Berlin.

Hill, R. (1952). The Elastic Behaviour of a Crystalline Aggregate, Proceedings of the Physical Society (London), A65, 349-354.

Kröner, E. (1958). Berechnung der elastischen Konstanten des Vielkristalls aus den Konstanten des Einkristalls, Zeitschrift für Physik, 151, 504-518.

Macherauch, E. and Müller, P. (1961). Das $\sin ^{2} \psi$-Verfahren der röntgenographischen Spannungsmessung, Zeitschrift für angewandte. Physik, 13, 305-312.

Macherauch, E., Wohlfarth, H. and Wolstieg, U. (1973). Zur zweckmäßigen Definition von Eigenspannungen, Härterei-Technische Mitteilungen, 28, 201-211.

Nathal, M. V., MacKay, R. A. and Garlick, R. G. (1985). Temperature Dependence of $\gamma / \gamma$ lattice Mismatch in Nickel-base Superalloys, Materials Science and Engineering, 75, 195-205.

Pintschovius, L., Hauk, V. and Krug, W. K. (1987). Neutron Diffraction Study of the Residual Stress State of a Cold-rolled Steel Strip, Materials Science and Engineering, 92, 1-12.

Pintschovius, L. (1992). Macrostresses, Microstresses and Stress Tensors, in: Measurement of Residual and Applied Stress Using Neutron Diffraction, M.T. Hutchings, A. D. Krawitz (eds.), 115-130, Kluwer Academic Publishers.

Reimers, W. (1989). Entwicklung eines Einkornmeß- und -auswerteverfahrens unter Anwendung von Beugungsmethoden zur Analyse von Deformationen und Eigenspannungen im Mikrobereich; Habilitationsschrift, Universität Dortmund.

Reimers, W. (1992a). Investigations of large grained samples - principles; in: Measurement of Residual and Applied Stress Using Neutron Diffraction, M.T. Hutchings, A.D. Krawitz (eds.), 159-170, Kluwer Academic Publishers.

Reimers, W., Crostack, H.-A., Wrobel, M. and Eckold, G. (1992b). Investigations of large grained samples - examples; in: Measurement of Residual and Applied Stress Using Neutron Diffraction, M.T. Hutchings, A. D. Krawitz (eds.), 263-276, Kluwer Academic Publishers. 